\title{
Land Treatment Digital Library
}

\section{A dynamic system to enter, store, retrieve, and analyze Federal land treatment data. More information and access to data available at: http://tdll.wr.usgs.gov}

\section{Overview of the Land Treatment Digital Library}

Across the country, public land managers make hundreds of decisions each year that influence landscapes and ecosystems within the lands they manage. Many of these decisions involve vegetation manipulations known as land treatments. Land treatments include activities such as removal or alteration of plant biomass, seeding burned areas, and herbicide applications. Data on these land treatments historically have been stored at local offices and gathering information across large spatial areas was difficult. These valuable data needed to be centralized and stored for Federal agencies involved in land treatments because these data are useful to land managers for policy and management and to scientists for developing sampling designs and studies.
In 2008, the Land Treatment Digital Library (LTDL) was created by the U.S. Geological Survey (USGS) to catalog information about land treatments on federal lands in the western United States. The flexible framework of the library allows for the storage of a wide variety of data in different formats. The library contains data in text, tabular, spatial, and image formats. Specific examples include project plans and implementation reports, monitoring data, spatial data files from geographic information systems, digitized paper maps, and digital images of land treatments. The data are entered by USGS employees and are accessible through a searchable website. The LTDL can be used to respond to information requests, conduct analyses and other forms of information syntheses, produce maps, and generate reports for federal managers, scientists, and other authorized users.
STEP 1: Land treatments conducted on $B L M$ lands have planning, implementation, and monitoring documentation.

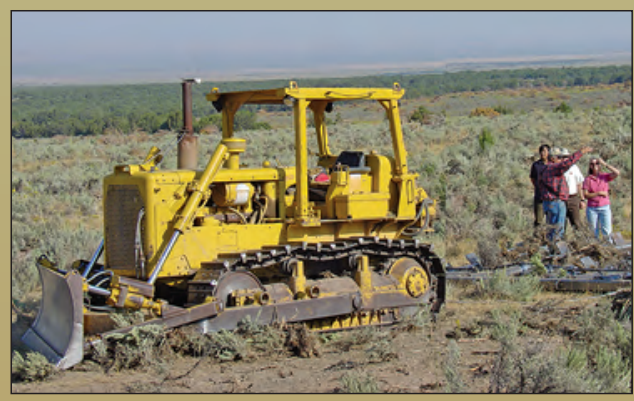

STEP 3: Data are entered into the LTDL connecting treatment spatial features and original documentation.

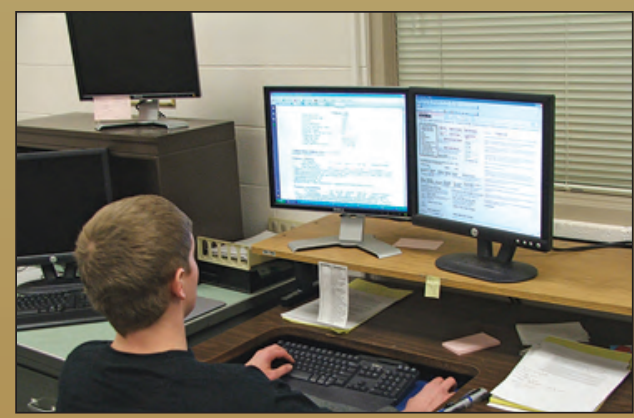

STEP 2: Paper documents are scanned and computer files are copied at field offices and stored as PDFs along with their spatial data.

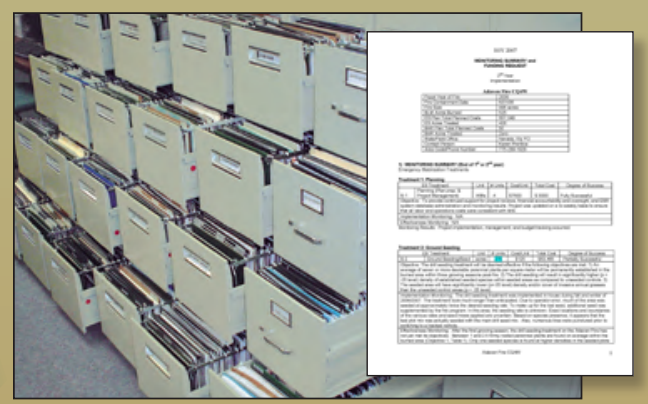

STEP 4: Data are uploaded to the LTDL website for viewing, exporting, or compiling datasets.

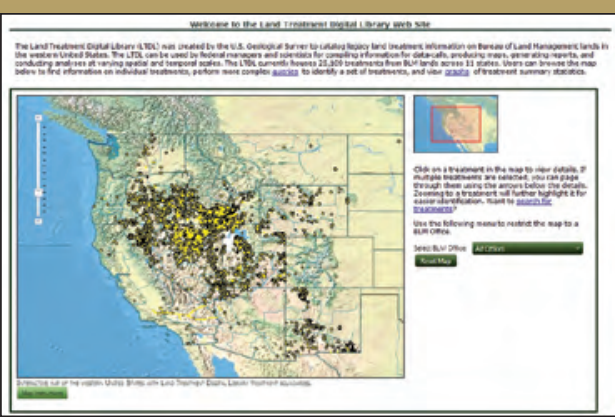




\section{Data Management:}

Available Records: Ultimately the LTDL will house all recorded BLM land treatment records. USGS employees add new data to the library and update current treatments as new information becomes available. Information is organized in a hierarchical fashion, such as multiple treatments tied to a larger project.

Spatial Data: All treatments are georeferenced for mapping and map queries. Spatial data are acquired from local offices when available or digitized from paper maps. Additionally, more than 30 different spatial attributes are added to the database in relation to each polygon, to enhance advanced queries. For example, elevation, average temperature, and land cover are calculated for each treatment and values with their percentages are added to the database. A user will know that a treatment contains 75 percent sagebrush and 25 percent juniper land cover. A description of the GIS layers and attributes generated is available at the LTDL website.

\section{Data Access:}

Library Website: The LTDL website, http://tdl.wr.usgs. gov/, is the portal through which users can search projects by location using an interactive map, using key words, or entering identifying metrics. Graphical summary information and detailed metrics on every treatment are also available on the site.

\section{For more information concerning the research in this report, contact the:}

Director, Forest and Rangeland Ecosystem

Science Center

U.S. Geological Survey

777 NW 9th Street

Corvallis, Oregon 97330
Website Features: In addition to the standard tabular data, other treatment information is available. Spatial data can be viewed online via the website or downloaded for use in a local GIS system. The library includes links to all available treatment documentation including plans, reports, monitoring data, and maps. The library stores digital images (photographs) with descriptions, such as location, direction, dates, and key words.

Data Permissions: Public users have access to summary reports, spatial data, and basic information on individual treatments via the LTDL website. Authorized users can also access advanced queries and detailed information either through the website or by working directly with the LTDL team. To learn more about how to access LTDL data, visit our website or contact the LTDL coordinator at ltdl_project@usgs.gov.

\section{Applications:}

The LTDL continues to assist land managers and scientists with data queries. These queries have been used in scientific research and land management, including planning and ecological assessments. For a full list of all publications and tools visit the products page on the LTDL website: http://ltdl.wr.usgs.gov/ products.aspx.
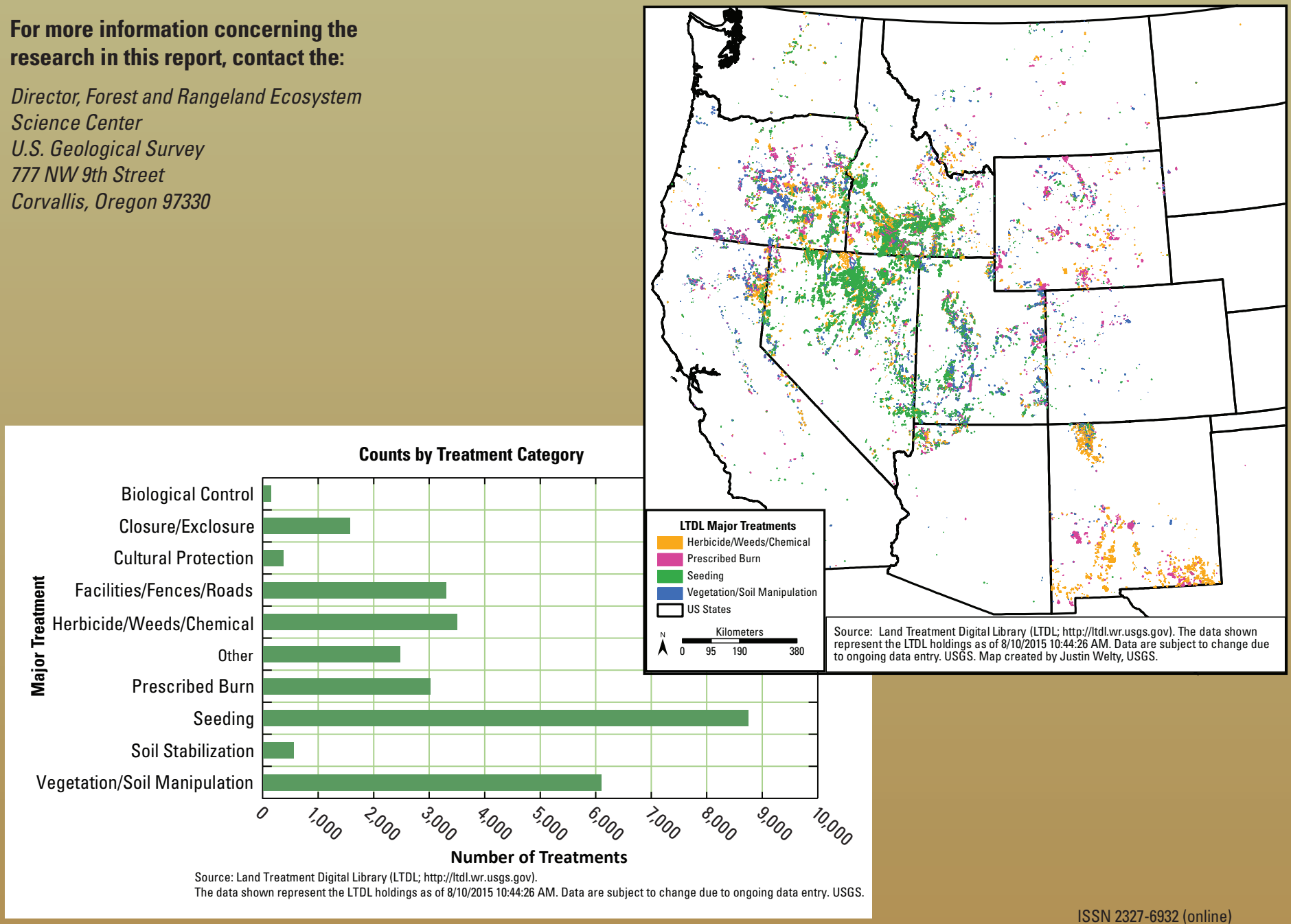

Source: Land Treatment Digital Library (LTDL; http://ltdl.wr.usgs.gov). 